\title{
Neuromuscular function during knee extension exercise after cold water immersion
}

Hitoshi Wakabayashi ${ }^{*}$, Titis Wijayanto ${ }^{2}$ and Yutaka Tochihara $^{3}$

\begin{abstract}
Background: Human adaptability to cold environment has been focused on in the physiological anthropology and related research area. Concerning the human acclimatization process in the natural climate, it is necessary to conduct a research assessing comprehensive effect of cold environment and physical activities in cold. This study investigated the effect of cold water immersion on the exercise performance and neuromuscular function during maximal and submaximal isometric knee extension.
\end{abstract}

Methods: Nine healthy males participated in this study. They performed maximal and submaximal $(20,40$, and $60 \%$ maximal load) isometric knee extension pre- and post-immersion in 23,26 , and $34{ }^{\circ} \mathrm{C}$ water. The muscle activity of the rectus femoris (RF) and vastus lateralis ( $\mathrm{VL}$ ) was measured using surface electromyography (EMG). The percentages of the maximum voluntary contraction (\%MVC) and mean power frequency (MPF) of EMG data were analyzed.

Results: The post-immersion maximal force was significantly lower in $23{ }^{\circ} \mathrm{C}$ than in 26 and $34^{\circ} \mathrm{C}$ conditions $(P<0.05)$. The post-immersion \%MVC of RF was significantly higher than pre-immersion during 60\% maximal exercise in 23 and $26^{\circ} \mathrm{C}$ conditions $(P<0.05)$. In the $\mathrm{VL}$, the post-immersion \%MVC was significantly higher than pre-immersion in 23 and $26^{\circ} \mathrm{C}$ conditions during $20 \%$ maximal exercise and in $26^{\circ} \mathrm{C}$ at 40 and $60 \%$ maximal intensities $(P<0.05)$. The postimmersion \%MVC of VL was significantly higher in $26^{\circ} \mathrm{C}$ than in $34^{\circ} \mathrm{C}$ at 20 and $60 \%$ maximal load $(P<0.05)$. The postimmersion MPF of RF during $20 \%$ maximal intensity was significantly lower in $23^{\circ} \mathrm{C}$ than in 26 and $34^{\circ} \mathrm{C}$ conditions $(P<0.05)$, and significantly different between three water temperature conditions at 40 and $60 \%$ maximal intensities $(P<0.05)$. The post-immersion MPF of VL during three submaximal trials were significantly lower in 23 and $26{ }^{\circ} \mathrm{C}$ than in $34^{\circ} \mathrm{C}$ conditions $(P<0.05)$.

Conclusions: The lower shift of EMG frequency would be connected with the decrease in the nerve and muscle fibers conduction velocity. To compensate for the impairment of each muscle fibers function, more muscle fibers might be recruited to maintain the working load. This might result in the greater amplitude of EMG after the cold immersion.

Keywords: Cold water immersion, Hypothermic skeletal muscle, Electromyography, Mean power frequency

\section{Background}

Human adaptability to cold environment has been studied well and summarized in numbers of paper [1-3]. There have been several approaches of the cold adaptation studies using "acclimatization" to the natural climate or "acclimation" to an experimentally induced cold environment, defined in the glossary of the International Union of

\footnotetext{
* Correspondence: wakabayashi@eng.hokudai.ac.jp

'Laboratory of Environmental Ergonomics, Faculty of Engineering, Hokkaido

University, N13 W8, Kita-ku, Sapporo 060-8628, Hokkaido, Japan

Full list of author information is available at the end of the article
}

Physiological Sciences [4]. The seasonal difference [5, 6], populations living in different climate [7-9], or people who work in cold work place $[10,11]$ have been studied for evaluating the cold acclimatization to the natural cold climate. On the other hand, cold acclimation studies have tested the change in physiological responses following a repeated cold exposure in a laboratory, mostly in resting condition [12, 13]. However, since human would have never acclimatized to cold alone without any physical activity, it is necessary to conduct a research assessing comprehensive effect of the physical activities in cold 
environment. Additionally, adaptation in the physical performance in cold would be one of the interesting research topics in the research area of physiological anthropology [14].

Concerning the importance of studying the cross adaptation of exercise and cold environment, this manuscript focuses on the performance and physiological characteristics during exercise in cold. There have been several review articles summarizing the human performance and physiological responses in cold environment [14-17]. The electromyography (EMG) technique has been often used for assessing the neuromuscular function during muscle activity in cold. When the skeletal muscle temperature is decreased, a lower shift in the EMG frequency has been uniformly reported [18-22]. However, inconsistent results (increased or decreased) have been observed in the amplitude of EMG [18, 19, 22-24]. The discrepancy might be explained by different experimental protocols including exercise type, cooling procedure, and measured muscle groups.

This study aimed to investigate the effect of cold water immersion on the exercise performance and neuromuscular function of the femoral muscles during maximal and submaximal isometric knee extension exercises.

\section{Methods}

\section{Participants}

Nine healthy males $(21.7 \pm 0.4$ years old; $167.8 \pm 2.3 \mathrm{~cm}$ height; $61.1 \pm 1.8 \mathrm{~kg}$ body weights; mean $\pm \mathrm{SE}$ ) participated in this study. All experimental protocols in this study were designed according to the principle of the Helsinki Declaration and approved by the Institutional Review Board of Kyushu University. All participants were informed of the experimental procedures and gave their written informed consent before participation.

\section{Experimental procedure}

Participants conducted three water temperature conditions $\left(23,26\right.$, and $\left.34{ }^{\circ} \mathrm{C}\right)$ of experiment on separate days in random order. We set 23,26 , and $34{ }^{\circ} \mathrm{C}$ water temperature as severe cold, mild cold, and thermoneutral condition, respectively. The $23^{\circ} \mathrm{C}$ condition was cold enough to induce shivering, but in $26^{\circ} \mathrm{C}$, no significant shivering was observed as shown in the previous report [12]. At least 1 week before the first test, participants were accustomed to perform one leg knee extension exercise using a specially designed device (Fig. 1). They sat on an aluminum-framed chair with cushion sheet, and their waist and chest were tied to the seat with polyester fiber belts. Their right ankle were attached to an end of stainless wire with a fiber belt, and the another end of wire was attached to a load cell (LUB-200 KB; Kyowa Electronic Instruments Co., Ltd., Japan) or weights thorough some pulley blocks.

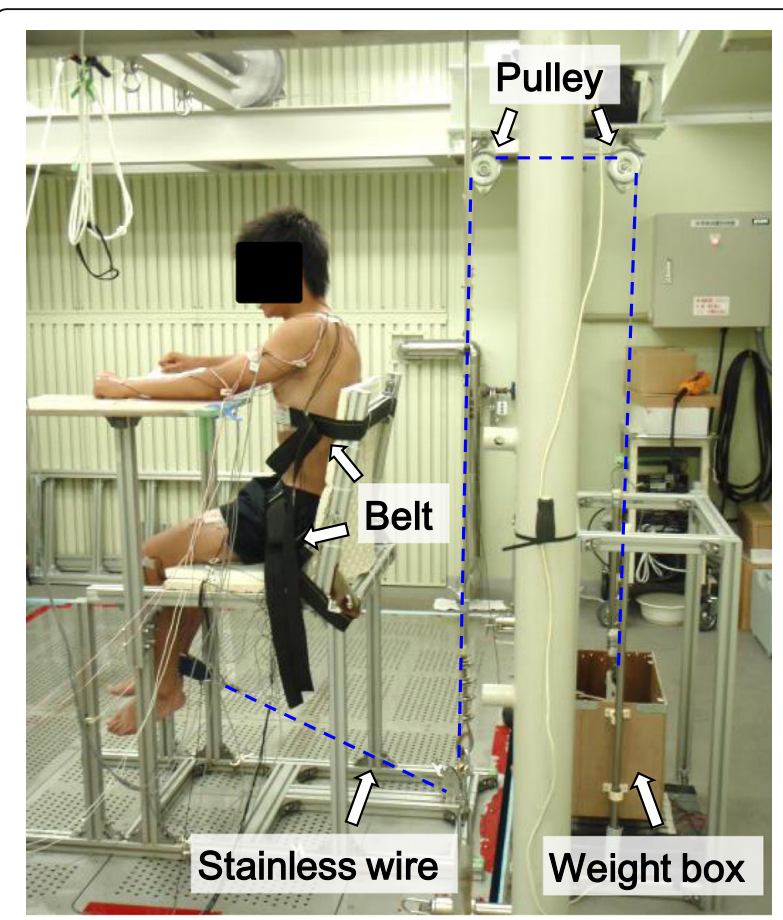

Fig. 1 Scheme of the knee extension device

Participants came to the laboratory at least $1 \mathrm{~h}$ before starting experiment and rested in a thermostatic chamber controlled at $27{ }^{\circ} \mathrm{C}$ and $50 \%$ relative humidity wearing ordinary swimming trunks. Before immersion, they performed maximal voluntary contraction (MVC) of isometric one leg extension for $5 \mathrm{~s}$ with $100^{\circ}$ knee joint angles. To motivate them into achieving maximal contraction levels, verbal encouragement by the instructors was provided. The force signal measured by the load cell were transferred to digital data using an A/D converter (SBL21512, Medical Try System, Japan) and were recorded using a personal computer (Think Centre A51 8425-51J. IBM, Japan) with a $1-\mathrm{kHz}$ sampling rate. Then, they performed 30-s submaximal isometric knee extension at three different exercise intensities (20, 40, and 60\% maximal load). They were asked to extend their knee to lift the weight attached to the end of the stainless wire and keep the position of $100^{\circ}$ knee joint angle as stable as possible for $30 \mathrm{~s}$ (Fig. 1).

Following the pre-immersion leg extension trials, participants were lowered into the water to their chest level using an electric winch attached to the movable floor, and they remained at rest on the chair in a thermostatic water tank for $60 \mathrm{~min}$. After the immersion, participants were pulled out from the water, and they performed post-immersion leg extension trials (maximal and submaximal), in the same protocol as the pre-immersion trials described above. 


\section{Measurements and analysis}

The muscle activity of the rectus femoris (RF) and vastus lateralis (VL) were measured during the experiment using surface electromyography (EMG). A pair of $5 \mathrm{~mm}$ diameter silver-silver-chloride surface EMG electrodes (Ag/AgCl Skin Electrode, NT-611T; Nihon Kohden Corp., Japan) was placed on the middle of each muscle belly. A reference electrode was placed on the clavicle. The skin cuticle was removed and cleaned with alcohol wipes so that the inter-electrode impedance was less than $20 \mathrm{k} \Omega$. The electrodes were covered with transparent waterproof film (Dressing tape MA-E100-A; Kyowa Limited., Japan) and putty for blocking water leakage through the lead wire of the electrodes (Fig. 2).

The raw EMG signals during the maximal and each submaximal knee extension trials were amplified with a multi-channel bioamplifier (Biotop 6R12-4; NEC San-ei Co. Ltd., Japan) and were filtered using band-pass filters ranging from 20 to $500 \mathrm{~Hz}$. The filtered EMG signals were transferred to digital data using an A/D converter (SBL21-512, Medical Try System., Japan) and were recorded using a personal computer (Think Centre A51 8425-51J. IBM, Japan) with a $1-\mathrm{kHz}$ sampling rate. The root mean square (RMS) was calculated every 512 points of EMG data. The peak 1024 msec RMS values of each muscle MVC were selected as normalizing values (100\%). The muscle activity level for each submaximal knee extension trial was presented as percentages of maximum voluntary contraction (\%MVC) every second for each muscle. The power spectrum of EMG signal during the submaximal isometric contraction was evaluated every second using the moving fast Fourier transfer analysis with Hamming window of 1024 points data. Then, mean power frequency (MPF) was calculated to ascertain changes in the frequency component. The \%MVC and MPF during the submaximal knee extension were averaged in the range of 5-15 s after starting

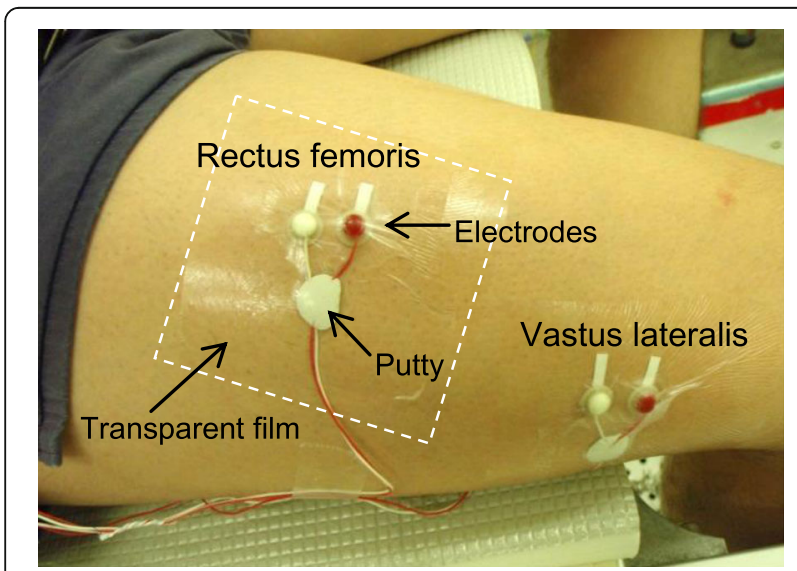

Fig. 2 Setting of surface EMG electrodes and waterproof technique using putty and transparent film contraction when the value were stable. The 5-15 s averaged \%MVC and MPF were used for the following statistical analysis.

\section{Statistics}

Data (maximal force, \%MVC, and MPF) were analyzed by a repeated measures two-way (water temperature $\times$ pre-post immersion) analysis of variance (ANOVA). This analysis was conducted separately for each RF and VL muscle and for exercise intensities. After determining the main effects, pair-wise post hoc tests were conducted between pre- and post-immersion at each water temperature (Fisher's post hoc least significant difference test) and among water temperature conditions within pre- and post-immersion (paired Student's $t$ tests). Significant differences were established at $P<0.05$. All data were presented as mean values and standard error (SE).

\section{Results}

\section{Maximal knee extension}

Maximal force during the maximal voluntary knee extension pre- and post-immersion, and post-immersion \%MVC in each muscle relative to the pre-immersion MVC are shown in Table 1. The post-immersion maximal force was significantly lower in $23^{\circ} \mathrm{C}$ condition than in 26 and $34{ }^{\circ} \mathrm{C}$ conditions $(P<0.05)$, while no statistical difference was observed between conditions at preimmersion trial. Maximal force tended to be lower in post compared to pre-immersion in $23{ }^{\circ} \mathrm{C}$ condition $(P=0.08)$, whereas no statistical difference was observed in 26 and $34{ }^{\circ} \mathrm{C}$ conditions. The post-immersion \%MVC of the RF was significantly greater in $26{ }^{\circ} \mathrm{C}$ condition compared to 23 and $34{ }^{\circ} \mathrm{C}$ conditions $(P<0.05)$. No statistical difference between conditions was observed in $\% \mathrm{MVC}$ of the VL.

\section{Submaximal knee extension}

The EMG amplitude (\%MVC) of RF and VL during submaximal isometric knee extension are shown in Figs. 3 and 4, respectively. The post-immersion \%MVC of RF was significantly higher than preimmersion during 60\% maximal knee extension in 23 and $26{ }^{\circ} \mathrm{C}$ conditions $(P<0.05$, Fig. $3 \mathrm{c})$. In the VL, the post-immersion \%MVC was significantly higher than pre-immersion in 23 and $26{ }^{\circ} \mathrm{C}$ conditions during $20 \%$ maximal exercise and in $26{ }^{\circ} \mathrm{C}$ during 40 and $60 \%$ maximal intensities $(P<0.05$, Fig. 4a-c). The postimmersion \%MVC of VL was significantly higher in $26{ }^{\circ} \mathrm{C}$ than in $34{ }^{\circ} \mathrm{C}$ during 20 and $60 \%$ maximal knee extensions $(P<0.05$, Fig. 4 a, c $)$.

The EMG mean power frequencies (MPF) of RF and $\mathrm{VL}$ during submaximal isometric knee extension are shown in Figs. 5 and 6, respectively. The MPF of RF and VL in 23 and $26{ }^{\circ} \mathrm{C}$ conditions were significantly lower 
Table 1 Pre- and post-immersion maximal force and post-immersion amplitude of electromyography in each muscle relative to the pre-immersion maximal voluntary contraction

\begin{tabular}{llll}
\hline Water temperature condition $\left({ }^{\circ} \mathrm{C}\right)$ & 23 & 26 & 34 \\
\hline Pre-immersion maximal force $(\mathrm{kg})$ & $53.0(2.7)$ & $53.8(2.5)$ & $53.9(2.7)$ \\
Post-immersion maximal force $(\mathrm{kg})$ & $48.8(2.9)^{\mathrm{b}, \mathrm{c}}$ & $52.7(2.9)^{\mathrm{a}}$ & $52.7(3.4)^{\mathrm{a}}$ \\
Post-immersion \%MVC in the RF (\%) & $98.8(5.6)^{\mathrm{b}}$ & $116.6(4.6)^{\mathrm{a}, \mathrm{c}}$ & $94.3(7.5)^{\mathrm{b}}$ \\
Post-immersion \%MVC in the VL (\%) & $102.3(6.5)$ & $116.2(6.6)$ & $98.5(7.0)$
\end{tabular}

Values are mean (SE). The $a$, b, and c represent the significant difference compared to 23,26 , and $34^{\circ} \mathrm{C}$, respectively $(P<0.05)$. The RF and VL are the abbreviations of the rectus femoris and the vastus lateralis, respectively

$\% M V C$ percentages of maximum voluntary contraction
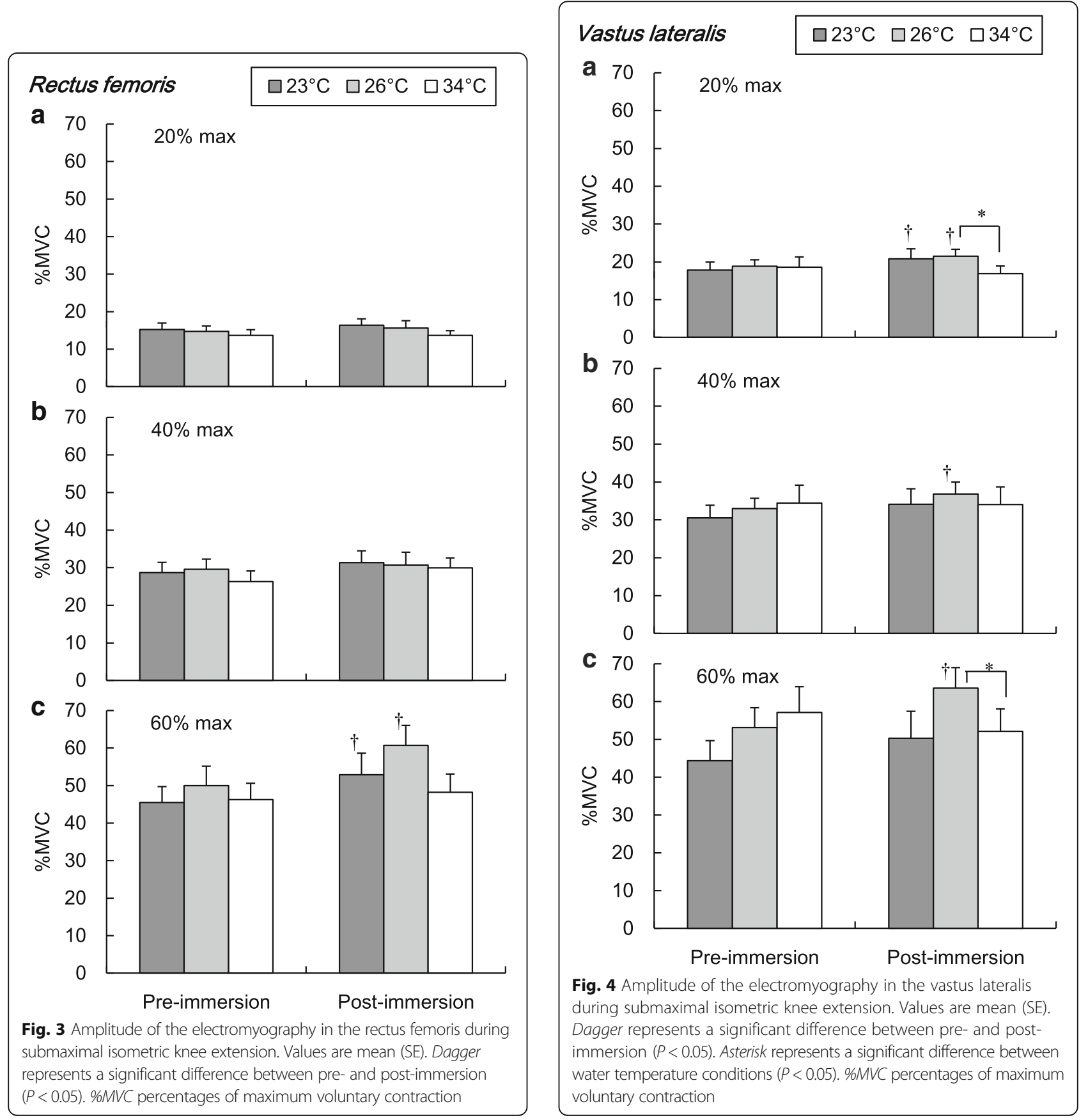


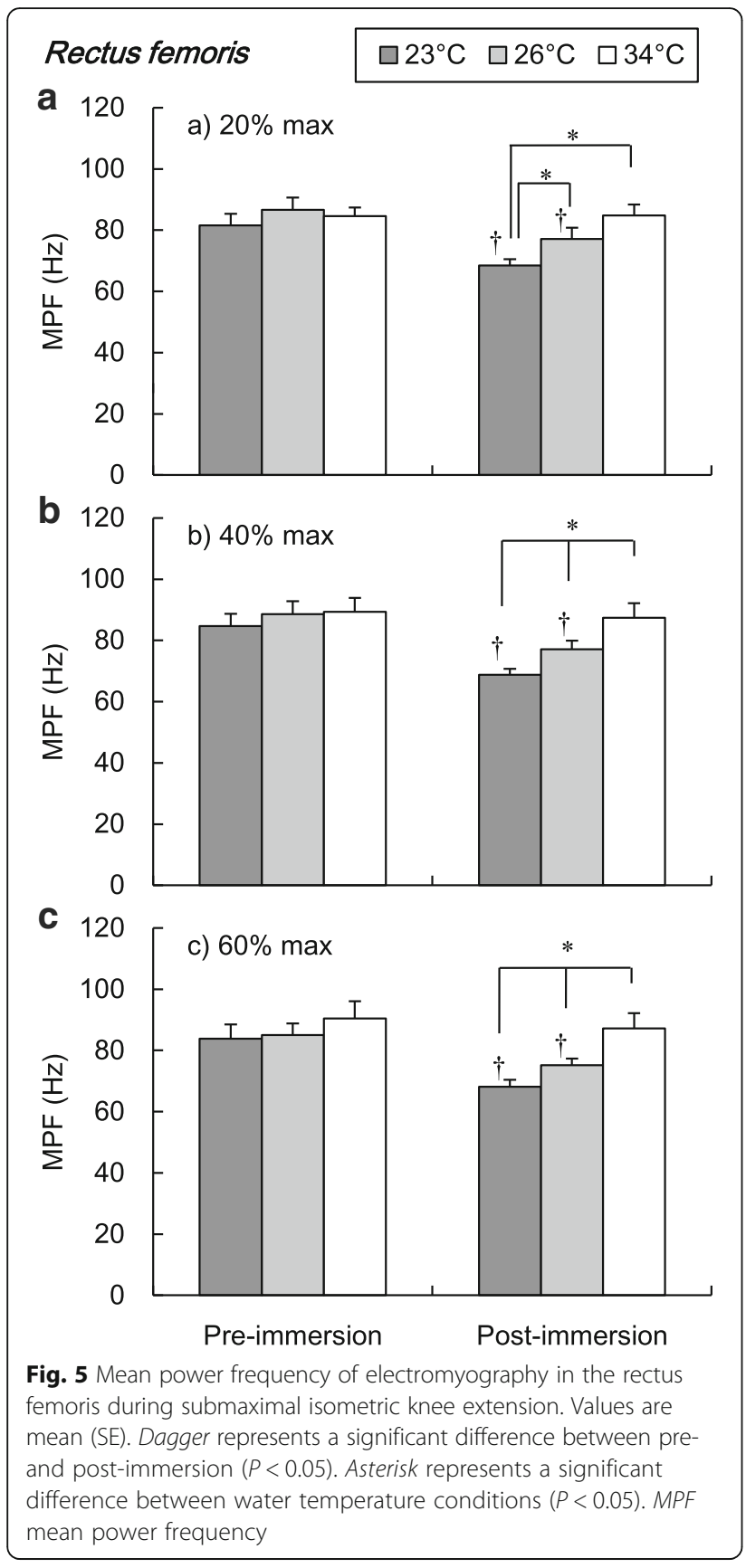

in post-immersion than pre-immersion trials in 20,40, and $60 \%$ maximal intensities $(P<0.05$, Figs. 5 and 6$)$. The post-immersion MPF of RF during $20 \%$ maximal intensity was significantly lower in $23{ }^{\circ} \mathrm{C}$ than in 26 and $34{ }^{\circ} \mathrm{C}$ conditions $(P<0.05$, Fig. $5 \mathrm{a})$ and significantly different between three water temperature conditions during 40 and $60 \%$ maximal intensities $(P<0.05$, Fig. 5 b, c). The post-immersion MPF of VL during three submaximal trials were significantly lower in 23 and $26{ }^{\circ} \mathrm{C}$ than in $34{ }^{\circ} \mathrm{C}$ conditions $(P<0.05$, Fig. $6 \mathrm{a}-\mathrm{c})$.

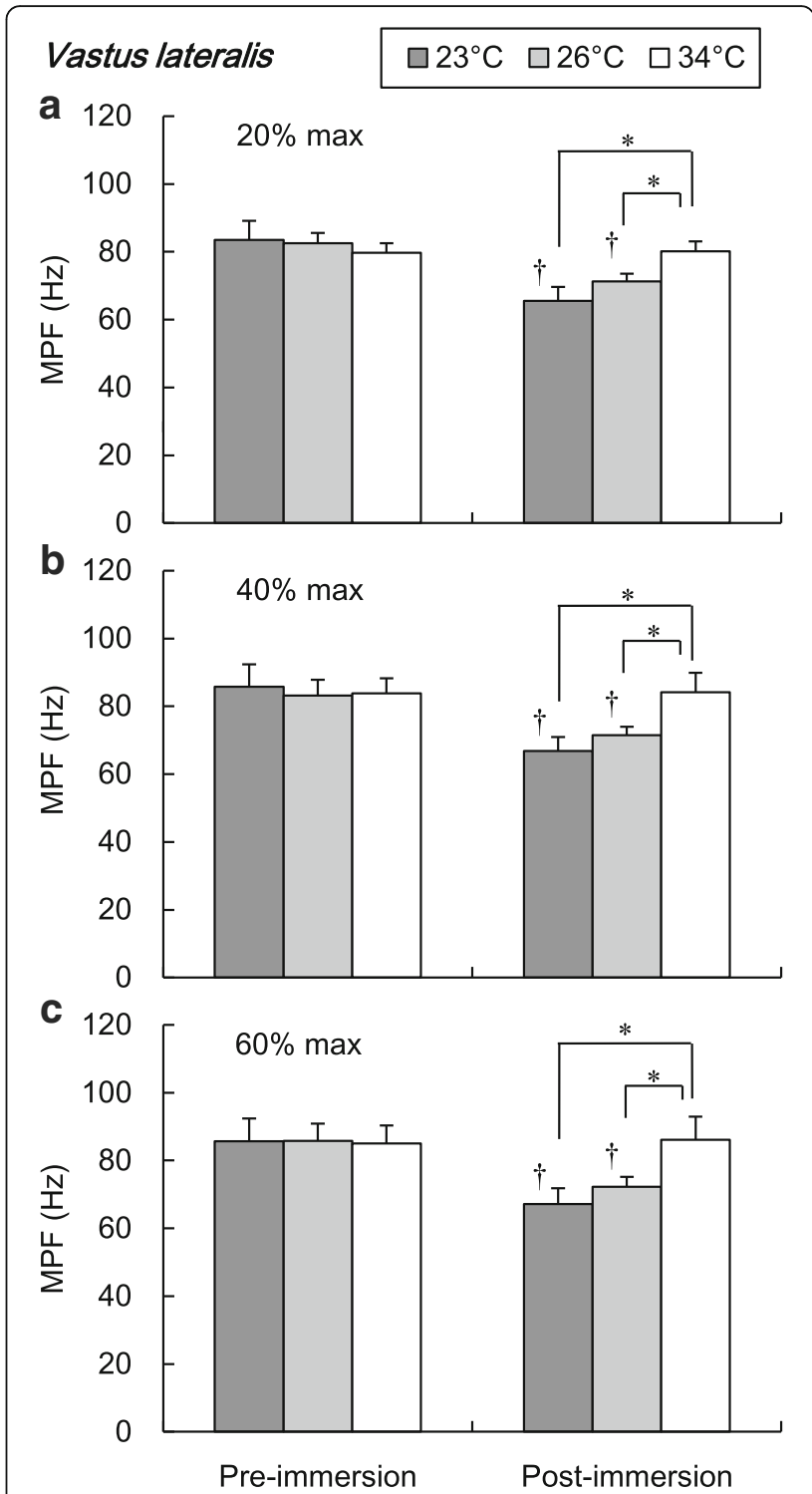

Fig. 6 Mean power frequency of electromyography in the vastus lateralis during submaximal isometric knee extension. Values are mean (SE). Dagger represents a significant difference between pre- and postimmersion $(P<0.05)$. Asterisk represents a significant difference between water temperature conditions $(P<0.05)$. MPF mean power frequency

\section{Discussion}

In this study, the effect of cold water immersion on the neuromuscular function during knee extension at maximal and submaximal intensities was assessed using the EMG technique. The maximal force after immersion was significantly lower in the $23^{\circ} \mathrm{C}$ condition compared to the thermoneutral $34{ }^{\circ} \mathrm{C}$ condition, whereas no difference was observed in the amplitude of EMG. During submaximal exercises, the amplitude of EMG was higher, and the power frequency was lower after cold water immersion compared to the thermoneutral condition. 
Bergh and Ekblom [25] tested the influence of muscle temperature on maximal muscle strength of knee extension exercise like our study. They reported a small decrease of MVC during isometric knee extension within the range of muscle temperature 30 to $39{ }^{\circ} \mathrm{C}$. In the present study, the reduction of the MVC was only observed after $23{ }^{\circ} \mathrm{C}$ cold water immersion, whereas no difference was observed between in $26{ }^{\circ} \mathrm{C}$ and thermoneutral conditions (Table 1). Based on previous researches and review articles, a muscle temperature of $27{ }^{\circ} \mathrm{C}$ is assumed to be a critical temperature for initiating reduction in the maximal isometric voluntary contraction $[14,15,17,26,27]$. Thus, probably the muscle temperature after $60 \mathrm{~min}$ immersion in $23{ }^{\circ} \mathrm{C}$ water might be below the critical muscle temperature for performing MVC. Additionally, since shivering was observed during immersion in $23^{\circ} \mathrm{C}$ water, the post-immersion data in $23^{\circ} \mathrm{C}$ condition might include the effect of muscle fatigue due to the shivering.

During submaximal isometric knee extension, significantly lower EMG frequency of the RF and VL was observed in colder water temperature conditions (Figs. 5 and 6). The lower shift of EMG frequency with lower muscle temperature has been reported a lot [18-22]. The lower shift of EMG frequency in the cold has been regarded as a result of the decrease in the nerve and muscle fibers conduction velocity $[20,28,29]$. Regarding the amplitude of EMG, there has been more variable observation in references which reported increased [19, 23] or decreased [18, 22, 24] amplitudes in cold environment. The discrepancy could be explained by different experimental protocols including exercise type, cooling procedure, and measured muscle groups. In this study, significant increase of the EMG amplitude was observed in both RF and VL in cold water conditions (Figs. 3 and 4). In detail, the effect of cold on the EMG amplitude was more clearly observed in the VL compared to the RF. The increase of the EMG amplitude might indicate the more muscle fiber recruitment for maintaining the given work load [30], since the function of each muscle fiber is suppressed due to the cold. In this study, the lower MPF in cold would reflect the suppression of the muscle fibers conduction velocity $[20,29]$. To compensate for the impairment of each muscle fibers function, more muscle fibers might be recruited to maintain the working load. This might result in the greater amplitude of EMG after the cold immersion, especially more in the VL rather than in the RF. The greater percentage of the fast twitch fiber in VL rather than in the RF [31] might explain the pronounced observation in the VL, since the role of fast twitch fiber is relatively more important in cold than in the thermoneutral condition, as explained below.

It has been reported that slow twitch fibers showed a greater reduction in the shortening velocity than fast twitch fiber in vitro [32], and faster muscle fibers are recruited at relatively lower velocity in cold water to maintain swimming speed [33, 34]. Since the slow twitch fibers have greater cold sensitivity and lower power output in cold, less cold sensitive and more powerful faster type fibers are recruited. Therefore, a greater number of fast twitch fibers need to be recruited in cold to generate the muscle powers for maintaining the work load. The recruitment of the fast twitch fiber in hypothermic skeletal muscle has been indirectly investigated in a study on muscle metabolism in cold [35]. The skeletal muscle oxygen uptake, which was assessed using near infrared spectroscopy, during isometric hand grip was gradually decreased as a function of the muscle temperature reduction [35]. This result would indicate a greater anaerobic contribution in the hypothermic skeletal muscle for maintaining the same work load as in the normothermic condition. Another report also supported the greater contribution of anaerobic metabolism with an evidence of greater minute ventilation per unit oxygen uptake $\left(V_{\mathrm{E}} / V \mathrm{O}_{2}\right)$ in cold water during incremental cycling exercise [36], since the $V_{\mathrm{E}} / V \mathrm{O}_{2}$ is known to increase above the anaerobic threshold [37].

Based on the observed neuromuscular function in the hypothermic skeletal muscle described above, a potential hypothesis of cold adaptation after physical activity in cold is discussed in this paragraph. It would be some kind of cross adaptation between exercise and cold environment. Concerning the greater recruitment of faster muscle fibers and anaerobic metabolism with hypothermic skeletal muscle [33-36], the repeated physical activity with reduction of muscle temperature might improve the anaerobic exercise tolerance and function of the faster type muscle fibers. There is an interesting research on the muscle fibers characteristic of Korean diving women who have routinely engaged in physical work in cold water [10]. Divers had a greater proportion of type IIx and fewer type IIa fibers compared to control group, whereas no group difference was in the type I fibers [10]. This result suggested that repeated physical activity in cold water might induce the shift of type II muscle fibers to the faster subgroup. However, since the diving work in cold water includes comprehensive effect of hypoxia induced by the intermittent breath holdings, further controlled researches are required to clarify the cross adaptation between exercise and cold.

\section{Conclusions}

This study investigated the effect of cold water immersion on the exercise performance and neuromuscular function. The maximal force was significantly lowered after cold water immersion. The lower shift of EMG frequency and greater EMG amplitude was observed in the femoral 
skeletal muscle during submaximal knee extension exercise after immersion in cold water.

\section{Abbreviations}

\%MVC: Percentages of maximum voluntary contraction; EMG: Electromyography; MPF: Mean power frequency; MVC: Maximal voluntary contraction; RF: Rectus femoris; RMS: Root mean square; VL: Vastus lateralis

\section{Acknowledgements}

The authors wish to thank all those who participated in this study. We would also like to express our gratitude to Mr. Mutsuhiro Fijiwara and Dr. Keita Ishibashi for their technical support.

\section{Funding}

This study was supported by a Grant-in-Aid for Scientific Research (No. 09J03584 No. 15K12671) from the Japan Society for the Promotion of Science.

\section{Availability of data and materials}

The datasets used and/or analyzed during the current study available from the corresponding author on reasonable request.

\section{Authors' contributions}

HW and YT designed the study. HW and TW conducted the experimental work. HW analyzed the data, prepared the figure, and drafted the manuscript. All authors participated in data interpretation and revised the manuscript. The final version of manuscript was approved by all authors.

\section{Competing interests}

The authors declare that they have no competing interests.

\section{Consent for publication}

All participants gave their written informed consent for publication before participation.

\section{Ethics approval and consent to participate}

All experimental protocols in this study were designed according to the principle of the Helsinki Declaration and approved by the Institutional Review Board of Kyushu University. All participants were informed of the experimental procedures and gave their written informed consent before participation.

\section{Publisher's Note}

Springer Nature remains neutral with regard to jurisdictional claims in published maps and institutional affiliations.

\section{Author details}

'Laboratory of Environmental Ergonomics, Faculty of Engineering, Hokkaido University, N13 W8, Kita-ku, Sapporo 060-8628, Hokkaido, Japan. ${ }^{2}$ Department of Mechanical and Industrial Engineering, Gadjah Mada University, Yogyakarta, Indonesia. ${ }^{3}$ Faculty of Design, Kyushu University, Fukuoka, Japan.

Received: 5 January 2017 Accepted: 13 June 2017

Published online: 23 June 2017

\section{References}

1. Hammel HT. Terrestrial animals in cold: recent studies of primitive man. In: Dill DB, Adolph EF, editors. Hand book of physiology. Washington DC: American Physiological Society; 1964. p. 413-34.

2. LeBlanc J. Adaptation of man to cold. In: Wang LCH, Hudson JW, editors. Strategies in cold. New York: Academic; 1978. p. 695-715.

3. Tipton MJ, Pandolf KB, Sawka MN, Werner J, Taylor NA. Physiological adaptation to hot and cold environments. In: Taylor NAS, Groeller H, editors. Physiological bases of human performance during work and exercise. London: Churchill Livingstone Elsevier; 2008. p. 379-400.

4. The commission for thermal physiology of the International Union of Physiological Sciences. Glossary of terms for thermal physiology, third edition. Jpn J Physiol. 2001;51(2):245-85.

5. van Ooijen AM, van Marken Lichtenbelt WD, van Steenhoven AA, Westerterp KR. Seasonal changes in metabolic and temperature responses to cold air in humans. Physiol Behav. 2004;82(2-3):545-53.
6. Nishimura T, Motoi M, Egashira Y, Choi D, Aoyagi K, Watanuki S. Seasonal variation of non-shivering thermogenesis (NST) during mild cold exposure. J Physiol Anthropol. 2015;34:11.

7. Hicks $C$, O'Connor W. Skin temperature of Australian Aboriginals under varying atmospheric conditions. Aust J Exp Biol Med Sci. 1938;16:1-18.

8. Scholander PF, Hammel HT, Hart JS, Lemessurier DH, Steen J. Cold adaptation in Australian aborigines. J Appl Physiol. 1958;13(2):211-8.

9. Khatun A, Ashikaga S, Nagano H, Hasib MA, Taimura A. Cold-induced vasodilation comparison between Bangladeshi and Japanese natives. J Physiol Anthropol. 2016;35:13.

10. Bae KA, An NY, Kwon YW, Kim C, Yoon CS, Park SC, Kim CK. Muscle fibre size and capillarity in Korean diving women. Acta Physiol Scand. 2003; 179(2):167-72

11. Lee JY, Lee HH. Korean women divers 'Haenyeo': bathing suits and acclimatization to cold. J Hum Environ Syst. 2014;17(1):001-11.

12. Wakabayashi $H$, Wijayanto $T$, Kuroki $H$, Lee JY, Tochihara Y. The effect of repeated mild cold water immersions on the adaptation of the vasomotor responses. Int J Biometeorol. 2012;56(4):631-7.

13. Tipton MJ, Wakabayashi H, Barwood MJ, Eglin CM, Mekjavic IB, Taylor NA. Habituation of the metabolic and ventilatory responses to cold-water immersion in humans. J Therm Biol. 2013;38(1):24-31.

14. Wakabayashi $\mathrm{H}, \mathrm{Oksa} \mathrm{J}$, Tipton MJ. Exercise performance in acute and chronic cold exposure. J Phys Fitness Sports Med. 2015;4(2):177-85.

15. Heus R, Daanen HA, Havenith G. Physiological criteria for functioning of hands in the cold: a review. Appl Ergon. 1995;26(1):5-13.

16. Drinkwater E. Effects of peripheral cooling on characteristics of local muscle. Med Sport Sci. 2008;53:74-88.

17. Racinais S, Oksa J. Temperature and neuromuscular function. Scand J Med Sci Sports. 2010;20 Suppl 3:1-18.

18. Petrofsky JS, Lind AR. The influence of temperature on the amplitude and frequency components of the EMG during brief and sustained isometric contractions. Eur J Appl Physiol Occup Physiol. 1980;44(2):189-200.

19. Winkel J, Jorgensen K. Significance of skin temperature changes in surface electromyography. Eur J Appl Physiol Occup Physiol. 1991;63(5):345-8.

20. Mucke R, Heuer D. Behaviour of EMG-parameters and conduction velocity in contractions with different muscle temperatures. Biomed Biochim Acta. 1989;48(5-6):S459-64.

21. Oksa J, Rintamaki H, Rissanen S. Muscle performance and electromyogram activity of the lower leg muscles with different levels of cold exposure. Eur J Appl Physiol Occup Physiol. 1997;75(6):484-90.

22. Petrofsky J, Laymon M. Muscle temperature and EMG amplitude and frequency during isometric exercise. Aviat Space Environ Med. 2005;76(11): 1024-30.

23. Bell DG. The influence of air temperature on the EMG/force relationship of the quadriceps. Eur J Appl Physiol Occup Physiol. 1993;67(3):256-60.

24. Drinkwater EJ, Behm DG. Effects of 22 degrees $C$ muscle temperature on voluntary and evoked muscle properties during and after high-intensity exercise. Appl Physiol Nutr Metab. 2007;32(6):1043-51.

25. Bergh U, Ekblom B. Influence of muscle temperature on maximal muscle strength and power output in human skeletal muscles. Acta Physiol Scand. 1979;107(1):33-7.

26. Clarke RS, Hellon RF, Lind AR. The duration of sustained contractions of the human forearm at different muscle temperatures. J Physiol. 1958;143(3):454-73.

27. Davies $C T$, Mecrow IK, White MJ. Contractile properties of the human triceps surae with some observations on the effects of temperature and exercise. Eur J Appl Physiol Occup Physiol. 1982;49(2):255-69.

28. De Jong RH, Hershey WN, Wagman $\mathrm{IH}$. Nerve conduction velocity during hypothermia in man. Anesthesiology. 1966;27(6):805-10.

29. Bigland-Ritchie B, Donovan EF, Roussos CS. Conduction velocity and EMG power spectrum changes in fatigue of sustained maximal efforts. J Appl Physiol Respir Environ Exerc Physiol. 1981;51(5):1300-5.

30. Rome LC. Influence of temperature on muscle recruitment and muscle function in vivo. Am J Physiol. 1990;259(2 Pt 2):R210-22.

31. Johnson MA, Polgar J, Weightman D, Appleton D. Data on the distribution of fibre types in thirty-six human muscles: an autopsy study. J Neurol Sci. 1973;18(1):111-29.

32. Ranatunga KW. The force-velocity relation of rat fast- and slow-twitch muscles examined at different temperatures. J Physiol. 1984;351:517-29.

33. Rome LC, Loughna PT, Goldspink G. Muscle fiber activity in carp as a function of swimming speed and muscle temperature. Am J Physiol. 1984; 247(2 Pt 2):R272-9. 
34. Rome LC, Choi IH, Lutz G, Sosnicki A. The influence of temperature on muscle function in the fast swimming scup. I. Shortening velocity and muscle recruitment during swimming. J Exp Biol. 1992;163:259-79.

35. Wakabayashi H, Nishimura T, Wijayanto T, Watanuki S, Tochihara Y. Effect of repeated forearm muscle cooling on the adaptation of skeletal muscle metabolism in humans. Int J Biometeorol. 2017:61(7):1261-7.

36. Fujimoto T, Sasaki Y, Wakabayashi H, Sengoku Y, Tsubakimoto S, Nishiyasu T. Maximal workload but not peak oxygen uptake is decreased during immersed incremental exercise at cooler temperatures. Eur J Appl Physiol. 2016;116(9):1819-27.

37. Whipp BJ, Davis JA, Wasserman K. Ventilatory control of the 'isocapnic buffering' region in rapidly-incremental exercise. Respir Physiol. 1989;76(3): $357-67$

Submit your next manuscript to BioMed Central and we will help you at every step:

- We accept pre-submission inquiries

- Our selector tool helps you to find the most relevant journal

- We provide round the clock customer support

- Convenient online submission

- Thorough peer review

- Inclusion in PubMed and all major indexing services

- Maximum visibility for your research

Submit your manuscript at www.biomedcentral.com/submit 